\title{
ABM Clinical Protocol \#18: Use of Antidepressants in Breastfeeding Mothers
}

\author{
Natasha K. Sriraman, Kathryn Melvin,2 \\ Samantha Meltzer-Brody, ${ }^{2,3}$ and the Academy of Breastfeeding Medicine
}

A central goal of The Academy of Breastfeeding Medicine is the development of clinical protocols for managing common medical problems that may impact breastfeeding success. These protocols serve only as guidelines for the care of breastfeeding mothers and infants and do not delineate an exclusive course of treatment or serve as standards of medical care. Variations in treatment may be appropriate according to the needs of an individual patient.

\section{Background}

$\mathbf{P}$ OSTPARTUM DEPRESSION (PPD) (SOMETIMES referred to as pregnancy-related mood disorder) is one of the most common and serious postpartum conditions, affecting 10-20\% of mothers within the first year of childbirth. ${ }^{1}$ Studies have found that up to $50 \%$ of women with PPD are undiagnosed. ${ }^{2}$ Risk factors include a prior history of depression (approximately $25-30 \%$ risk of recurrence), ${ }^{3,4}$ including PPD, and depression during pregnancy. Other risk factors include recent stressful life events, lack of social support, unintended pregnancy, ${ }^{5}$ and women who are economically stressed, disadvantaged, low income, or black. ${ }^{6}$ Moreover, studies of economically disadvantaged families have shown that approximately $25 \%$ of women will have ongoing depressive symptoms that last well beyond the initial postpartum year. ${ }^{7}$

Treatment approaches include nonpharmacological therapies such as interpersonal psychotherapy or cognitive behavioral therapy, pharmacological therapies, or a combination of both. Antidepressant medications are one of the most commonly prescribed pharmacologic treatments of PPD. The mother and her provider should work together to make an individually tailored choice. Breastfeeding mothers may be concerned about continuing and/or starting medication for PPD. Some providers are reluctant to prescribe for lactating mothers due to lack of information about antidepressants and breastfeeding. The risks of untreated depression, the risks of the medication to the breastfeeding dyad, and the benefits of treatment must be fully considered when making treatment decisions.

This protocol will discuss the spectrum of disease, emphasize the importance of screening, and provide evidence- based information recommendations for treatment of PPD in breastfeeding mothers.

\section{Spectrum of disease}

There has been controversy about whether PPD is a distinct entity. In the Diagnostic and Statistical Manual of Mental Disorders, 4th and 5th editions (DSM-IV and V, respectively), PPD is considered a subtype of major depression, and there is an associated specifier to denote onset in the postpartum period. ${ }^{8}$ The newer DSM-V expanded the definition of PPD to include onset of symptoms during pregnancy through 4 weeks postpartum. ${ }^{9}$ Diagnosis may be further complicated by other comorbid conditions, including anxiety and bipolar disorder. Postpartum mood disorders are common in the postpartum period but differ according to timing and severity of symptoms and encompass a wide range of disorders. ${ }^{2,8,10}$

"Postpartum blues" is a condition characterized by emotional changes, insomnia, appetite loss, and feelings of being overwhelmed that can affect $30-80 \%$ of women. ${ }^{7,8}$ It is a transient condition that usually peaks on postpartum Day 5 and resolves by Day 10. Unlike PPD, postpartum blues does not adversely affect infant care.

"Postpartum depression" is a major depressive episode that impairs social and occupational functioning. Symptoms cause significant distress and can include suicidal ideation. If untreated, symptoms may persist beyond 14 days and can last several months to a year. ${ }^{1}$

"Postpartum psychosis" is a psychiatric emergency and is characterized by paranoia, hallucinations, delusions, and suicidal ideation, with the potential risk of suicide and/or

\footnotetext{
${ }^{1}$ Department of Pediatrics, Children's Hospital of The King's Daughters/Eastern Virginia Medical School, Norfolk, Virginia.

${ }^{2}$ Department of Psychiatry, University of North Carolina Chapel Hill School of Medicine, Chapel Hill, North Carolina.

${ }^{3}$ Perinatal Psychiatry Program, University of North Carolina Chapel Hill Center for Women's Mood Disorders, Chapel Hill, North Carolina.
} 
infanticide. It can occur in one to three of every 1,000 deliveries and usually has a rapid onset (within hours to a few weeks) after delivery. ${ }^{7,8}$ Women with postpartum psychosis may have a prior history of postpartum psychosis or bipolar disorder, but in some women there is no prior psychiatric history. ${ }^{11,12}$ Approximately $25-50 \%$ of women with bipolar disorder are at risk of developing postpartum psychosis. ${ }^{13}$

"Postpartum intrusive thoughts" and "obsessive compulsive disorder" commonly occur in women, but with a wide range of severity of symptoms they are concerns for postpartum women. Intrusive or obsessive thoughts are unwelcome and involuntary thoughts, images, or unpleasant ideas that may become obsessions. These thoughts are usually upsetting or distressing to the woman, and they can be difficult to manage or eliminate. ${ }^{14,15}$

\section{Screening for $P P D$}

Research confirms that most mothers $(80 \%)$ are comfortable with the idea of being screened for depression. ${ }^{1}$ Internationally, guidelines and authorities recommend screening for PPD. ${ }^{16-18}$

Although definitive evidence of benefit is limited, the American College of Obstetricians and Gynecologists recommends that clinicians screen patients at least once during the perinatal period for depression and anxiety symptoms using a standardized, validated tool ${ }^{19}$ For the first time, a large U.S. multicenter study of screening and follow-up care for PPD in a family practice setting has shown improved maternal outcomes at 12 months. ${ }^{20}$ (I) (Quality of evidence [levels of evidence I, II-1, II-2, II-3, and III] is based on the U.S. Preventive Services Task Force Appendix A Task Force Ratings ${ }^{21}$ and is noted throughout this protocol in parentheses.)

Most physicians and maternal/child healthcare providers recognize the detrimental effects of PPD and agree that screening new mothers is within the scope of their practice. ${ }^{22,23}$ The American Academy of Pediatrics and the U.S. Surgeon General's Office recognize and call for the early identification and treatment of mental health disorders, including PPD. ${ }^{24,25}$ It is important that screening for PPD be done systematically globally as detection and treatment have been shown to be beneficial in many countries. ${ }^{26}$ (I)

\section{Screening instruments}

The screening instrument that has been most studied throughout the world is the Edinburgh Postnatal Depression Scale (EPDS) ${ }^{7,27}$ The EPDS is free, considered to be in the public domain, and available in many languages and has crosscultural validity. It has 10 questions to be completed by the mother based on symptoms over the past 7 days and takes approximately 5 minutes to complete. ${ }^{27}$ There are multiple points of contact in which screening can occur. In wellchildcare visits, EPDS screening could occur during the 1-, 2-, $4-$, and 6-month visits. ${ }^{716-18,28-30}$ The cesarean section incision check at 2 weeks and the postpartum visit at $4-8$ weeks are also important screening opportunities. The EPDS can be readily administered and has demonstrated validity to detect postpartum mood disorders at as early as $4-8$ weeks postpartum. ${ }^{30,31}$ (II-3) Either a score of 10 or higher or a positive response to Question 10 about suicidal thoughts is considered positive and indicates that the mother may be suffering from a depressive illness of varying severity. ${ }^{32}$ (II-3) Providers caring for the infant must refer a mother with a positive screen for appropriate care.

\section{Effects of PPD}

In addition to the obvious adverse effects on the mother, PPD affects the child, spouse and/or partner, and other family members. It can cause family dysfunction, prevent effective mother-baby bonding, lead to early cessation of breastfeeding, and adversely affect infant growth and brain development. ${ }^{733-36}$ Rates of paternal depression are higher when the mother has PPD, which can compound the negative effects of depression on children. Infants of depressed mothers show less engagement and eye contact with their mother and are at risk for failure to thrive, attachment disorder, and development delay. ${ }^{2}$

A shared neuroendocrine mechanism among maternal mood, oxytocin levels, and maternal affect during breastfeeding has been demonstrated. ${ }^{37}$ This strengthens the position that women with depression would benefit from early and sustained support with breastfeeding. Likewise, women with negative early breastfeeding experiences may be more likely to have depressive symptoms at 2 months postpartum; thus women experiencing breastfeeding difficulties should be screened for depressive symptoms. ${ }^{33}$

\section{Clinical Approach to Treating PPD}

Once a woman is identified as being at risk for PPD, treatment choices must be considered and offered to her. For mild to moderate depression in the breastfeeding mother, psychology/cognitive behavioral therapy, if available, should be considered as first-line therapy. ${ }^{38}$ (II-2)

\section{Treatment}

\section{Nonpharmacological}

Psychological therapy. Psychological therapy is effective for the treatment of major depressive disorder in the postpartum period, and different types of therapy seem equally effective. ${ }^{39-41}$ (I) There are three approaches to administration of psychological therapy in the postpartum period, including interpersonal therapy, cognitive behavioral therapy, and psychodynamic psychotherapy (nondirective therapy). ${ }^{39-47}$ Nonpharmacological treatment is not harmful to the infant and is often acceptable to mothers with PPD.

Infant feeding considerations. Breastfeeding difficulties and perinatal depression symptoms often present together, and management of depression should include a discussion of the mother's experience of breastfeeding. Some mothers with depression find that breastfeeding enhances bonding and improves their mood, whereas others find breastfeeding to be difficult. For dyads struggling with milk production and latch issues, efforts should be undertaken to simplify feeding plans to ensure that mother and infant have time to enjoy one another. The demands of nighttime breastfeeding can be challenging for mothers for whom interruption of sleep is a major trigger for mood symptoms. In these cases, it may be helpful to arrange for another caregiver to feed the infant once at night, allowing the mother to receive 5-6 hours of uninterrupted sleep. A caregiver may also bring the infant to the mother to feed at the breast and then assume responsibility for 
settling the baby back to sleep, thereby minimizing maternal sleep disruption. (III)

\section{Medications}

If psychological/cognitive behavioral therapy is unavailable, symptoms are severe, or mothers refuse this therapy, antidepressants are an effective option. Many factors must be considered when choosing an antidepressant during breastfeeding. All antidepressants are present in human milk to some extent. Data to inform clinical decisions are derived primarily from case reports or case series. Therefore, the initial treatment choice should be based on an informed clinical approach that takes into account the patient's previous treatments for depression, especially use during the pregnancy, the targeted symptoms, family history of depression and their experiences with antidepressants, current and past medical disorders, current medications, allergies, side effects of the medications, and maternal wishes. An individualized risk-benefit analysis of the treatments must be conducted (Table 1). ${ }^{48}$ (I)

\section{Clinical Factors Affecting Antidepressant Choice}

- Obtain a psychiatric history with a focus on previous episodes of mood and anxiety disorders and effective treatment interventions. If psychotropic medications were used, determine what treatments were effective with a tolerable side effect profile. Past treatment response is often the best predictor of future response. ${ }^{48}$ (II-2)

- Obtain a family history of psychiatric illness and treatment response. An immediate family member's history may be indicative of the mother's treatment response. ${ }^{48}$ (II-2)

- Consider the primary symptoms that the medication will be targeting and its potential side effect profile.

- Choose psychotropic medications with an evidence base in lactating women. Older medications with available data are preferred over newer antidepressants with limited safety information.

\section{Choosing an Antidepressant During Lactation}

When considering the use of any medication in a lactating woman, providers must consider both maternal and infant safety factors. The medication must be both efficacious for the mother and safe for the infant. Although infant serum levels of psychotropic medication are the most accurate measure of infant exposure, it is often difficult to measure infant serum levels in routine clinical practice. However, factors affecting the passage of medication into human milk must be considered, including the following:

1. Route of drug administration and pharmacokinetics ${ }^{49}$ :

- absorption rate

- half-life and peak serum time

- dissociation constant

- volume of distribution

- molecular size

- degree of ionization

- $\mathrm{pH}$ of plasma (7.4) and milk (6.8)

- solubility of the drug in water and in lipids

- binding to plasma protein
2. Amount of drug received by the infant in human milk ${ }^{49}$ :

- milk yield

- colostrum versus mature milk

- concentration of the drug in the milk

- how well the breast was emptied during the previous feeding

- the infant's ability to absorb, detoxify, and excrete the drug.

Up-to-date information about medication use during lactation is easily available from the Internet on TOXNET LACTMED (http://toxnet.nlm.nih.gov/newtoxnet/lactmed .htm) (available in English) and e-lactancia (http://e-lactan cia. org/) (available in both English and Spanish).

Most antidepressant studies provide milk levels, or milk to mother's plasma ratio, that are not constant and depend on factors such as dose, frequency, duration of dosing, maternal variation in drug disposition, drug interactions, and genetic background. Few studies provide infant serum levels, although they are the best measure of infant exposure. ${ }^{49}$

\section{Specific Antidepressants}

Data from a recent meta-analysis indicated that all antidepressants were detected in milk but that not all were found in infant serum. ${ }^{50}$ Infant serum levels of nortriptyline, paroxetine, and sertraline were undetectable in most cases. Infant serum levels of citalopram and fluoxetine exceeded the recommended $10 \%$ maternal level in $17 \%$ and $22 \%$ of cases, respectively. Few adverse outcomes were reported for any of the antidepressants. Conclusions could not be drawn for other antidepressants due to an insufficient number of cases. There is little or no evidence that ethnic or regional "medicines" are safe or effective; thus their use by healthcare providers is strongly cautioned. (II-2) For specific antidepressant medications, see Table 1.

\section{Recommendations for Antidepressant Treatment in Lactating Women}

- Current evidence suggests that untreated maternal depression can have serious and long-term effects on mothers and infants and that treatment may improve outcomes for mothers and infants. Therefore treatment is strongly preferred. (II-2)

- However, it is important not to label mothers who are only suffering from mild cases of postpartum blues as "depressed." We must make a distinction. For women with mild symptoms who are in the first 2 weeks postpartum, close follow-up, rather than initiation of antidepressant medication, is suggested. (II-2)

- When available and when symptoms are in the mild to moderate range, psychological/cognitive behavioral therapy is the first line of treatment for lactating women as it carries no known risk for the infant. Mothers must be monitored and reevaluated. If they are not improving or their symptoms are worsening, antidepressant drug treatment should be considered. (II-2)

- Both psychological/cognitive behavioral therapy and antidepressant medication are recommended for women with moderate to severe symptoms or for whom there are current stressors or interpersonal issues that psychological 


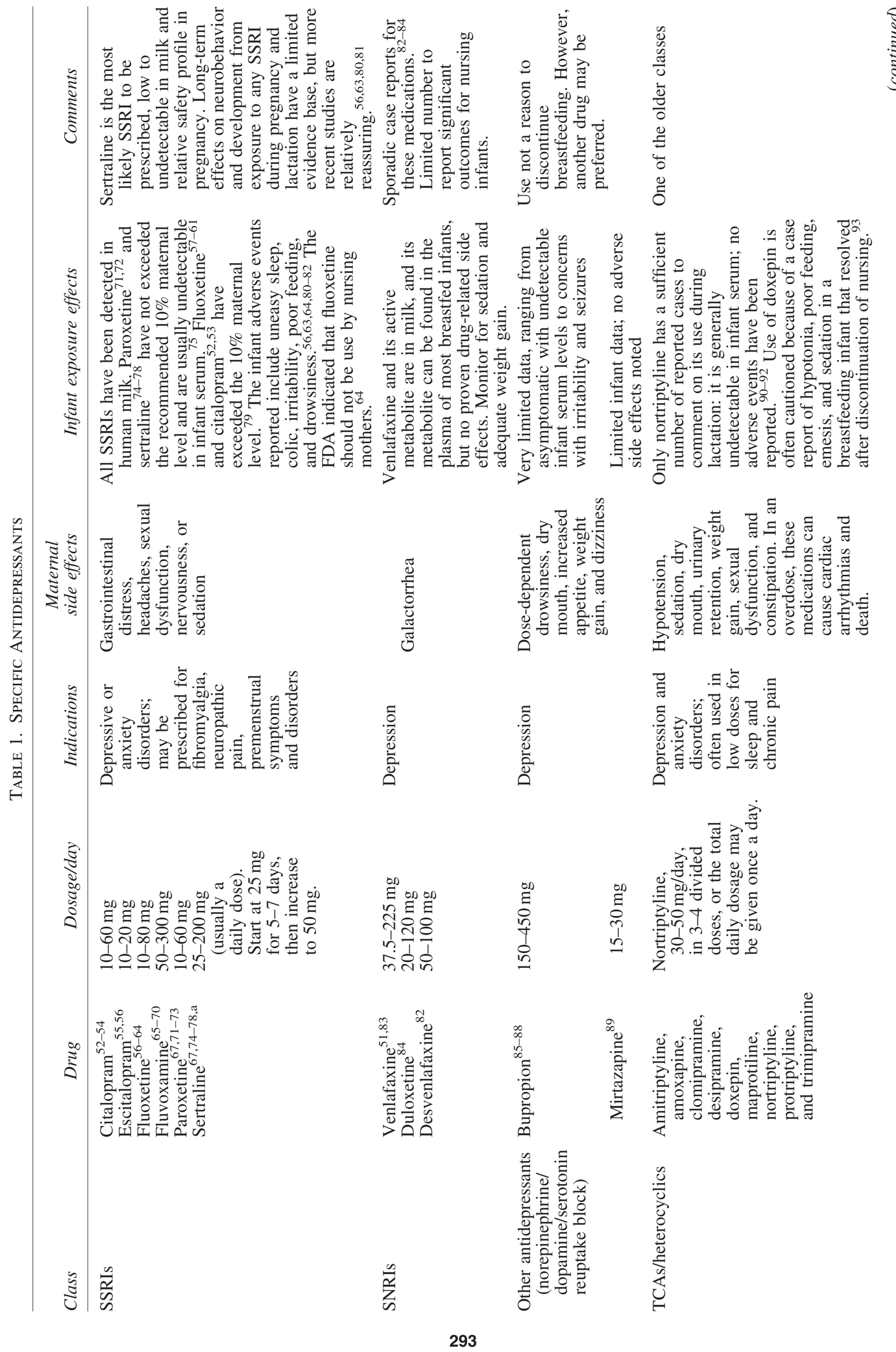




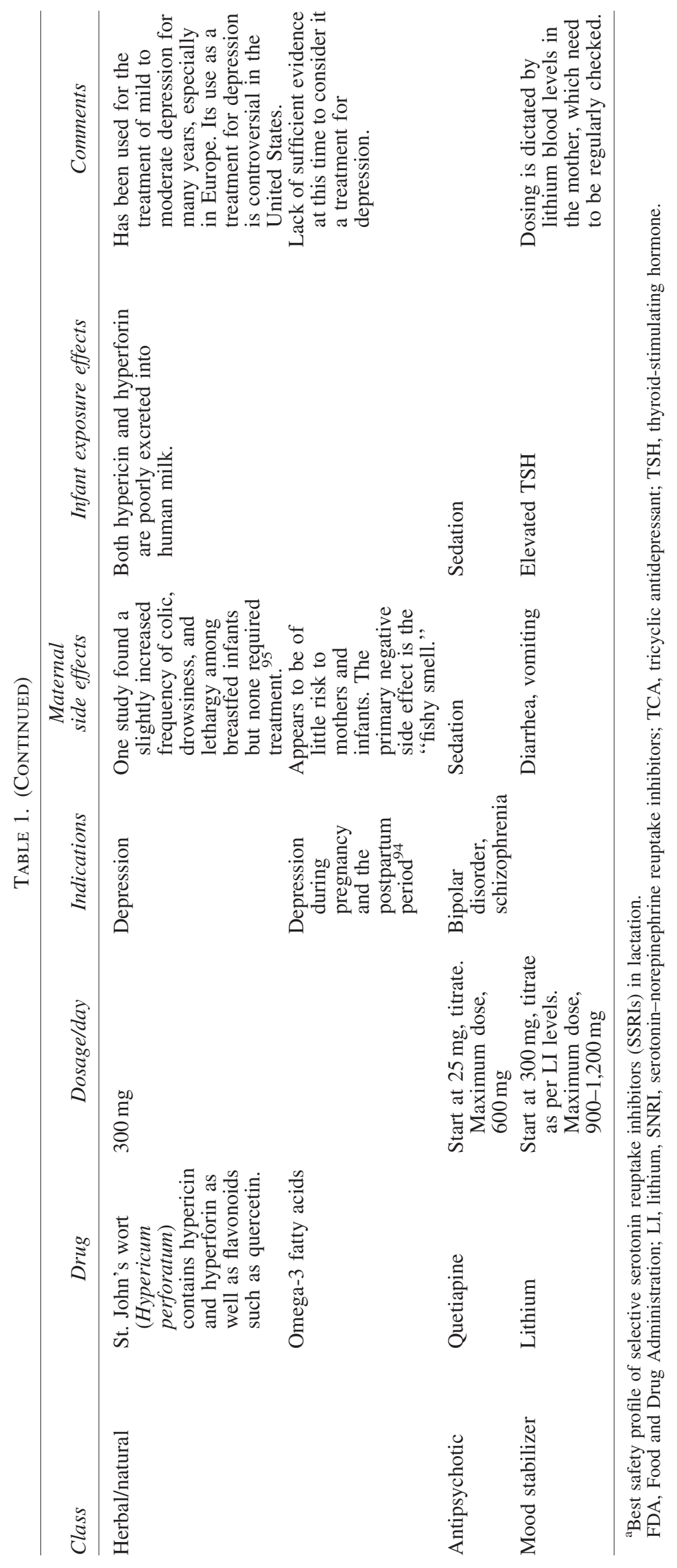


therapy may help address. Maternal lactation status should not delay treatment. (II-2)

- Women with moderate to severe symptoms may require only antidepressant drug treatment. In the setting of moderate to severe depression, the benefits of treatment likely outweigh the risks of the medication to the mother or infant.

- There is no widely accepted algorithm for antidepressant medication treatment of depression in lactating women. An individualized risk-benefit analysis must be conducted in each situation and take into account the mother's clinical history and response to treatment, the risks of untreated depression, the risks and benefits of breastfeeding, the benefits of treatment, the known and unknown risks of the medication to the infant, and the mother's wishes.

- If a mother has no history of antidepressant treatment, an antidepressant such as sertraline that has evidence of lower levels in human milk and infant serum and few side effects is an appropriate first choice. (II-2) Sertraline has the best safety profile during lactation. The recommended starting dose is $25 \mathrm{mg}$ for 5-7 days to avoid side effects, which then can be increased to $50 \mathrm{mg} /$ day.

Table 2. Resources for Women's Mental Health and Postpartum Depression Help

Resource Description $U R L$

Web sites
International Marcé Society
for Perinatal Mental Health

Maternal and Child Health

Bureau, U.S. Health Resources and Services Administration

National Suicide Prevention

Lifeline, U.S. Substance

Abuse and Mental Health

Services Administration

Postpartum Support

International

Postpartum Depression

Online Support Group

Mental Health America

Beyond Blue

Books
Primarily a multidisciplinary group of healthcare providers interested in promoting, facilitating, and communicating about research in all aspects of the mental health of women, their infants and partners around the time of childbirth.

Handbook entitled "Depression During and After Pregnancy: A Resource for Women, Their Families, and Friends"

1-800-273-TALK (8255)

Information and resources on postpartum depression for providers, mothers, fathers, and families. Includes live chats and help for new parents. Access help according to state. PSI Warmline (weekdays only) 800-944-4PPD (4773)

A privately funded online support group that offers information, support, and assistance to those dealing with postpartum mood disorders and their families, friends, physicians, and counselors

The nonprofit Mental Health America is concerned with fathers' mental health as well as mothers.

A national initiative in Australia to raise awareness of anxiety and depression, providing resources for recovery, management and resilience

Bennett SS, Indman P. Beyond the Blues: Understanding and Treating Prenatal and Postpartum Depression \& Anxiety. Moodswings, San Jose, CA, 2011.

Cooper PJ, Murray L, eds. Postpartum Depression and Child Development. Guilford, New York, 1999.

Kendall-Tackett KA. A Breastfeeding-Friendly Approach to Postpartum Depression. Praeclarus Press, Amarillo, TX, 2015.

Kendall-Tackett KA. Depression in New Mothers, 2nd ed. Routledge, London, 2010.

Kleiman K. Therapy and the Postpartum Woman: Notes on Healing Postpartum Depression for Clinicians and the Women Who Seek Their Help. Routledge, Abingdon, United Kingdom, 2008.

Kleiman KR. The Postpartum Husband: Practical Solutions for Living with Postpartum Depression. Xlibris, Bloomington, IN, 2001.

Shields B. Down Came the Rain: My Journey Through Postpartum Depression. Hyperion, New York, 2006.

Wiegartz PS, Gyoerkoe KL, Miller LJ. The Pregnancy and Postpartum Anxiety Workbook: Practical Skills to Help You Overcome Anxiety, Worry, Panic Attacks, Obsessions, and Compulsions. New Harbinger Publications, Oakland, CA, 2009. 
- If a mother has been successfully treated with a particular selective serotonin reuptake inhibitor, tricyclic antidepressant, or serotonin-norepinephrine uptake inhibitor in the past, the data regarding this particular antidepressant should be reviewed, and it should be considered as a firstline treatment if there are no contraindications.

- Mothers who were being treated with a selective serotonin reuptake inhibitor, tricyclic antidepressant, or serotoninnorepinephrine uptake inhibitor during pregnancy with good symptom control should continue on the same agent during breastfeeding. It is important to reassure the mother that exposure to the antidepressant in breastmilk is far less than exposure to the antidepressant during pregnancy. Moreover, ongoing treatment of the mood disorder is critical for the health of both mother and baby. Mothers should be provided information regarding the known and unknown risks and benefits of the treatment to make an informed decision.

- Mothers should be monitored carefully in the initial stages of treatment for changes in symptoms, including worsening of symptoms. Specifically, women with histories of bipolar disorder, which may be undiagnosed, are at increased risk of developing an episode of depression, mania, or psychosis in the postpartum period. Although this situation is rare, mothers and partners should be made aware of the symptoms to watch for such as increased insomnia, delusions, hallucinations, racing thoughts, and talking/moving fast. Women experiencing such symptoms should contact their mental health provider immediately.

- The mother's provider should communicate with the infant's provider to facilitate monitoring and follow-up. Infants should be monitored carefully by the physician/ healthcare worker, including carefully following growth. Serum levels are not indicated on a regular basis without a clinical indication or concern. In addition, in most cases, the serum level would not provide helpful information unless it is a psychotropic that has a documented therapeutic window and laboratory norms (i.e., tricyclic antidepressants).

- A strategy that may be used to decrease infant exposure based on breastfeeding pharmacokinetic reports is medication administration immediately after feedings. (III)

- There are several Web-based and book references available for professionals and mothers to assist in gaining knowledge and help regarding these issues (Table 2).

\section{Conclusions and Suggestions for Future Research}

Despite many publications about antidepressants and breastfeeding, the scientific literature continues to lack the depth of robust large-scale studies for clinicians and mothers to make confident decisions about individual medications. Multiple reviews of the literature broadly suggest tricyclic antidepressants and selective serotonin reuptake inhibitors are relatively safe, and all recommend individual risk-benefit assessments. $^{51}$

Future research that would help guide clinical practice includes:

1. Randomized clinical trials in lactating women for any class of antidepressant that include the following: a. Sufficient control for level of depression

b. Provision of drug, information on infant serum levels, the amount detected in human milk, maternal serum levels, and the timing of sampling

c. Information on infant consumption in the milk

d. Information on infant behavioral outcomes

e. Evaluation of impact of continued breastfeeding on mitigating infant withdrawal symptoms for those mothers treated antenatally.

2. Study reasons mothers and clinicians elect to defer treatment in lactating mothers and follow-up behavioral outcomes of these infants.

\section{References}

1. Gjerdingen DK, Yawn BP. Postpartum depression screening: Importance, methods, barriers, and recommendations for practice. J Am Board Fam Med 2007;20: 280-288.

2. Chaudron LH, Szilagyi PG, Tang W, et al. Accuracy of depression screening tools for identifying postpartum depression among urban mothers. Pediatrics 2010;125: e609-e617.

3. Wisner KL, Perel JM, Peindl KS, et al. Prevention of recurrent postpartum depression: A randomized clinical trial. J Clin Psychiatry 2001;62:82-86.

4. Marcus SM. Depression during pregnancy: Rates, risks, and consequences-Motherisk Update 2008. Can J Clin Pharmacol 2009;16:e15-e22.

5. Oppo A, Mauri M, Ramacciotti D, et al. Risk factors for postpartum depression: The role of the Postpartum Depression Predictors Inventory-Revised (PDPI-R). Results from the Perinatal Depression-Research and Screening Unit (PNDReScU) study. Arch Womens Ment Health 2009;12: 239-249.

6. Cutler CB, Legano LA, Dreyer BP, et al. Screening for maternal depression in a low education population using a two item questionnaire. Arch Womens Ment Health 2007;10: 277-283.

7. Earls MF; Committee on Psychosocial Aspects of Child and Family Health American Academy of Pediatrics. Incorporating recognition and management of perinatal and postpartum depression into pediatric practice. Pediatrics 2010;126:1032-1039.

8. Mishina H, Takayama JI. Screening for maternal depression in primary care pediatrics. Curr Opin Pediatr 2009;21: 789-793.

9. American Psychiatric Association. Diagnostic and Statistical Manual of Mental Disorders (DSM-V). American Psychiatric Publishing, Arlington, VA, 2013.

10. Sriraman NK. Postpartum depression: Why pediatricians should screen new moms. Cont Pediatr 2012;29:40-46.

11. Sharma V. Treatment of postpartum psychosis: Challenges and opportunities. Curr Drug Saf 2008;3:76-81.

12. Chaudron LH, Pies RW. The relationship between postpartum psychosis and bipolar disorder: A review. J Clin Psychiatry 2003;64:1284-1292.

13. Jones I, Craddock N. Familiarity of the puerperal trigger in bipolar disorder: Results of a family study. Am J Psychiatry 2001;158:913-917.

14. Abramowitz JS, Meltzer-Brody S, Leserman J, et al. Obsessional thoughts and compulsive behaviors in a sample of women with postpartum mood symptoms. Arch Womens Ment Health 2010;13:523-530. 
15. Russell EJ, Fawcett JM, Mazmanian D. Risk of obsessivecompulsive disorder in pregnant and postpartum women: A meta-analysis. J Clin Psychiatry 2013;74:377-385.

16. National Institute for Health and Clinical Excellence. Postnatal Care: Routine Postnatal Care of Women and Their Babies (CG37). National Institute for Health and Clinical Excellence, London, 2006.

17. Royal Australian College of General Practitioners. Guidelines for Preventive Activities in General Practice. Royal Australian College of General Practitioners, East Melbourne, Australia, 2012.

18. Scottish Intercollegiate Guidelines Network. Management of Perinatal Mood Disorder. Scottish Intercollegiate Guidelines Network, Edinburgh, 2012.

19. Screening for perinatal depression. Committee Opinion No. 630. American College of Obstetricians and Gynecologists. Obstet Gynecol 2015;125:1268-1271. Available at www .acog.org/Resources-And-Publications/Committee-Opinions/ Committee-on-Obstetric-Practice/Screening-for-PerinatalDepression (accessed June 1, 2015).

20. Yawn BP, Dietrich AJ, Wollan P, et al. TRIPPD: A practicebased network effectiveness study of postpartum depression screening and management. Ann Fam Med 2012;10: 320-329.

21. Appendix A Task Force Ratings. Guide to Clinical Preventive Services: Report of the U.S. Preventive Services Task Force, 2nd ed. Available at www.ncbi.nlm.nih.gov/ books/NBK15430/ (accessed May 27, 2015).

22. Olson AL, Kemper KJ, Kelleher KJ, et al. Primary care pediatricians' roles and perceived responsibilities in the identification and management of maternal depression. Pediatrics 2002;110:1169-1176.

23. Chaudron LH, Szilagyi PG, Campbell AT, et al. Legal and ethical considerations: Risks and benefits of postpartum depressions screening at well-child visits. Pediatrics 2007;119:123-128.

24. U.S. Public Health Service. Report of the Surgeon General's Conference on Children's Mental Health: A National Action Agenda. U.S. Department of Health and Human Services, Washington, DC, 2000. Available at www.ncbi.nlm.nih.gov/ books/NBK44233/ (accessed May 27, 2015).

25. Committee on the Psychosocial Aspects of Child and Family Health and Task Force on Mental Health. Policy statement-The future of pediatrics: Mental health competencies for pediatric primary care. Pediatrics 2009;124: 410-421.

26. Myers ER, Aubuchon-Endsley N, Bastian LA, et al. Efficacy and Safety of Screening for Postpartum Depression. Comparative Effectiveness Reviews, No. 106. Agency for Healthcare Research and Quality, Rockville, MD, 2013. Available at www.ncbi.nlm.nih.gov/books/NBK137724/ (accessed May 27, 2015).

27. Cox JL, Holden JM, Sagovsky R. Detection of postnatal depression. Development of the 10-item Edinburgh Postnatal Depression Scale. Br J Psychiatry 1987;150:782-786. Available at http://pesnc.org/wp-content/uploads/EPDS.pdf (accessed May 27, 2015).

28. Hagan JF Jr, Shaw JS, Duncan P, eds. Bright Futures: Guidelines for Health Supervision of Infants, Children, and Adolescents, 3rd ed. American Academy of Pediatrics, Elk Grove Village, IL, 2008.

29. Sheeder J, Kabir K, Stafford B. Screening for postpartum depression at well-child visits: Is once enough during the first 6 months of life? Pediatrics 2009;123:e982-e988.
30. Freeman MP, Wright R, Watchman M, et al. Postpartum depression assessments at well-baby visits: Screening feasibility, prevalence, and risk factors. J Womens Health (Larchmt) 2005;14:929-935.

31. Dennis CL. Can we identify mothers at risk for postpartum depression in the immediate postpartum period using the Edinburgh Postnatal Depression Scale? J Affect Disord 2004;78:163-169.

32. Jardri R, Pelta J, Maron M, et al. Predictive validation study of the Edinburgh Postnatal Depression Scale in the first week after delivery and risk analysis for postnatal depression. J Affect Disord 2006;93:169-176.

33. Watkins S, Meltzer-Brody S, Zolnoun D, Stuebe A. Early breastfeeding experiences and postpartum depression. $\mathrm{Ob}$ stet Gynecol 2011;118:214-221.

34. Trapolini T, McMahon CA, Ungerer JA. The effect of maternal depression and marital adjustment on young children's internalizing and externalizing behaviour problems. Child Care Health Dev 2007;33:794-803.

35. Minkovitz CS, O'Campo PJ, Chen YH, et al. Associations between maternal and child health status and patterns of medical care use. Ambul Pediatr 2002;2:85-92.

36. Kavanaugh M, Halterman JS, Montes G, et al. Maternal depressive symptoms are adversely associated with prevention practice and parenting behaviors for preschool children. Ambul Pediatr 2006;6:32-37.

37. Stuebe AM, Grewen K, Meltzer-Brody S. Association between maternal mood and oxytocin response to breastfeeding. J Womens Health (Larchmt) 2013;22:352-361.

38. Office of Disease Prevention and Health Promotion, U.S. Department of Health and Human Services. Healthy People 2020. Maternal, Infant, and Child Health. Available at http:// healthypeople.gov/2020/topicsobjectives2020/overview .aspx?topicid = 26 (accessed May 27, 2015).

39. Dennis CL, Ross LE, Grigoriadis S. Psychosocial and psychological interventions for treating antenatal depression. Cochrane Database Syst Rev 2007;(3):CD006309.

40. Brandon AR, Freeman MP. When she says "no" to medication: Psychotherapy for antepartum depression. Curr Psychiatry Rep 2011;13:459-466.

41. Cuijpers P, Brannmark JG, van Straten A. Psychological treatment of postpartum depression: A meta-analysis. $J$ Clin Psychol 2008;64:103-118.

42. O'Hara MW, Schlechte JA, Lewis DA, et al. Prospective study of postpartum blues. Biologic and psychosocial factors. Arch Gen Psychiatry 1991;48:801-806.

43. Dekker JJ, Koelen JA, Van HL, et al. Speed of action: The relative efficacy of short psychodynamic supportive psychotherapy and pharmacotherapy in the first 8 weeks of a treatment algorithm for depression. J Affect Disord 2008;109: 183-188.

44. O'Hara MW, Stuart S, Gorman LL, et al. Efficacy of interpersonal psychotherapy for postpartum depression. Arch Gen Psychiatry 2000;57:1039-1045.

45. Brandon AR, Ceccotti N, Hynan LS, et al. Proof of concept: Partner-assisted interpersonal psychotherapy for perinatal depression. Arch Womens Ment Health 2012;15: 469-480.

46. Mulcahy R, Reay RE, Wilkinson RB, et al. A randomised control trial for the effectiveness of group interpersonal psychotherapy for postnatal depression. Arch Womens Ment Health 2010;13:125-139.

47. Grote NK, Swartz HA, Geibel SL, et al. A randomized controlled trial of culturally relevant, brief interpersonal 
psychotherapy for perinatal depression. Psychiatr Serv 2009;60:313-321.

48. Burt VK, Suri R, Altshuler L, et al. The use of psychotropic medications during breast-feeding. Am J Psychiatry 2001;158:1001-1009.

49. Hale T. Medications and Mothers Milk, 16th ed. Hale Publishing, Plano, TX, 2014.

50. Weissman AM, Levy BT, Hartz AJ, et al. Pooled analysis of antidepressant levels in lactating mothers, breast milk, and nursing infants. Am J Psychiatry 2004;161:1066-1078.

51. Molyneaux E, Howard LM, McGeown HR, et al. Antidepressant treatment for postnatal depression. Cochrane Database Syst Rev 2014;9:CD002018.

52. Heikkinen $\mathrm{T}$, Ekblad U, Kero $\mathrm{P}$, et al. Citalopram in pregnancy and lactation. Clin Pharmacol Ther 2002;2: 184-191.

53. Lee A, Woo J, Ito S. Frequency of infant adverse events that are associated with citalopram use during breastfeeding. Am J Obstet Gynecol 2004;190:218-221.

54. Schmidt K, Olesen OV, Jensen PN. Citalopram and breastfeeding: Serum concentration and side effects in the infant. Biol Psychiatry 2000;47:164-165.

55. Bellantuono C, Bozzi F, Orsolini L, et al. The safety of escitalopram during pregnancy and breastfeeding: A comprehensive review. Hum Psychopharmacol 2012;27:534-539.

56. Brent NB, Wisner KL. Fluoxetine and carbamazepine concentrations in a nursing mother/infant pair. Clin Pediatr (Phila) 1998;37:41-44.

57. Kristensen JH, Ilett KF, Hackett LP, et al. Distribution and excretion of fluoxetine and norfluoxetine in human milk. $\mathrm{Br}$ J Clin Pharmacol 1999;48:521-527.

58. Epperson CN, Jatlow PI, Czarkowski K, et al. Maternal fluoxetine treatment in the postpartum period: Effects on platelet serotonin and plasma drug levels in breastfeeding mother-infant pairs. Pediatrics 2003;112:e425.

59. Heikkinen T, Ekblad U, Palo P, Laine K. Pharmacokinetics of fluoxetine and norfluoxetine in pregnancy and lactation. Clin Pharmacol Ther 2003;73:330-337.

60. Hendrick V, Stowe ZN, Altshuler LL, et al. Fluoxetine and norfluoxetine concentrations in nursing infants and breast milk. Biol Psychiatry 2001;50:775-782.

61. Suri R, Stowe ZN, Hendrick V, Hostetter A, et al. Estimates of nursing infant daily dose of fluoxetine through breast milk. Biol Psychiatry 2002;52:446-451.

62. Lester BM, Cucca J, Andreozzi L, et al. Possible association between fluoxetine hydrochloride and colic in an infant. J Am Acad Child Psychiatry 1993;32:1253-1255.

63. Chambers CD, Anderson PO, Thomas RG, et al. Weight gain in infants whose mothers take fluoxetine. Pediatrics 1999;104:e61.

64. Nightingale SL. Fluoxetine labeling revised to identify phenytoin interaction and to recommend against use in nursing mothers. JAMA 1994;271:106.

65. Arnold LM, Suckow RF, Lichtenstein PK. Fluvoxamine concentrations in breast milk and in maternal and infant sera. J Clin Psychopharmacol 2000;20:491-493.

66. Hagg S, Granberg K, Carleborg L. Excretion of fluvoxamine into breast milk. Br J Clin Pharmacol 2000;49:286-288.

67. Hendrick V, Fukuchi A, Altshuler L, et al. Use of sertraline, paroxetine and fluvoxamine by nursing women. $\mathrm{Br} J \mathrm{Psy}$ chiatry 2001;179:163-166.

68. Piontek CM, Wisner KL, Perel JM, Peindl KS. Serum fluvoxamine levels in breastfed infants. J Clin Psychiatry 2001;62:111-113.
69. Yoshida K, Smith B, Kumar RC. Fluvoxamine in breastmilk and infant development. Br J Clin Pharmacol 1997;44: 210-211.

70. Wright S, Dawling S, Ashford JJ. Excretion of fluvoxamine in breast milk. Br J Clin Pharmacol 1991;31:209.

71. Misery S, Kim J, Riggs KW, Kostaras X. Protein levels in postpartum depressed women, breast milk, and infant serum. J Clin Psychiatry 2000;61:828-832.

72. Stowe ZN, Cohen LS, Hostettler A, et al. Paroxetine in human breast milk and nursing infants. Am J Psychiatry 2000;157: 185-189.

73. Merlob P, Stahl B, Sulkes J. Paroxetine during breastfeeding: Infant weight gain and maternal adherence to counsel. Eur J Pediatr 2004;163:135-139.

74. Epperson CN, Anderson GM, McDougle CJ. Sertraline and breast-feeding. N Engl J Med 1997;336:1189-1190.

75. Stowe ZN, Owens MJ, Landry JC, et al. Sertraline and desmethylsertraline in human breast milk and nursing infants. Am J Psychiatry 1997; 154:1255-1260.

76. Epperson N, Czarkowski KA, Ward-O'Brien D, et al. Maternal sertraline treatment and serotonin transport in breast-feeding mother-infant pairs. Am J Psychiatry 2001;158:1631-1637.

77. Wisner KL, Perel JM, Blumer J. Serum sertraline and Ndesmethylsertraline levels in breast-feeding mother-infant pairs. Am J Psychiatry 1998;155:690-692.

78. Dodd S, Stocky A, Buist A, et al. Sertraline analysis in the plasma of breast-fed infants. Aust N Z J Psychiatry 2001;35: 545-546.

79. Ito S, Koren G. Antidepressants and breast-feeding. Am J Psychiatry 1997;154:1174.

80. Olivier JD, Akerud H, Kaihola H, et al. The effects of maternal depression and maternal selective serotonin reuptake inhibitor exposure on offspring. Front Cell Neurosci 2013;7:73.

81. Austin MP, Karatas JC, Mishra P, et al. Infant neurodevelopment following in utero exposure to antidepressant medication. Acta Paediatr 2013;102:1054-1059.

82. Rampono J, Teoh S, Hackett LP, et al. Estimation of desvenlafaxine transfer into milk and infant exposure during its use in lactating women with postnatal depression. Arch Womens Ment Health 2011;14:49-53.

83. Ilett KF, Kristensen JH, Hackett LP, et al. Distribution of venlafaxine and its O-desmethyl metabolite in human milk and their effects in breastfed infants. Br J Clin Pharmacol 2002;53:17-22.

84. Boyce PM, Hackett LP, Ilett KF. Duloxetine transfer across the placenta during pregnancy and into milk during lactation. Arch Womens Ment Health 2011;14:169-172.

85. Baab SW, Peindl KS, Piontek CM, et al. Serum bupropion levels in two breastfeeding mother-infant pairs. J Clin Psychiatry 2002;63:910-911.

86. Neuman G, Colantonio D, Delaney S, et al. Bupropion and escitalopram during lactation. Ann Pharmacother 2014;48: 928-931.

87. Chaudron LH, Schoenecker CJ. Bupropion and breastfeeding: A case of a possible infant seizure. J Clin Psychiatry 2004;65:881-882.

88. Davis MF, Miller HS, Nolan PE Jr. Bupropion levels in breast milk for four mother-infant pairs: More answers to lingering questions. J Clin Psychiatry 2009;70:297-298.

89. Aichhorn WMD, Whitworth ABM, Weiss UMD, et al. Mirtazapine and breast-feeding. Am J Psychiatry 2004;161: 2325 . 
90. Wisner KL, Perel JM. Nortriptyline treatment of breastfeeding women. Am J Psychiatry 1996;153:295.

91. Wisner KL, Perel JM. Serum nortriptyline levels in nursing mothers and their infants. Am J Psychiatry 1991;148: 1234-1236.

92. Wisner KL, Perel JM, Findling RL, Hinnes RL. Nortriptyline and its hydroxymetabolites in breastfeeding mothers and newborns. Psychopharmacol Bull 1997;33:249-251.

93. Frey OR, Scheidt P, von Brenndorff AI. Adverse effects in a newborn infant breast-fed by a mother treated with doxepin. Ann Pharmacother 1999;33:690-693.

94. Freeman MP, Hibbeln JR, Wisner KL, et al. Randomized dose-ranging pilot trial of omega-3 fatty acids for postpartum depression. Acta Psychiatr Scand 2006;113:31-35.

95. Lee A, Minhas R, Matsuda N, et al. The safety of St. John's wort (Hypericum perforatum) during breast-feeding. J Clin Psychiatry 2003;64:966-968.
ABM protocols expire 5 years from the date of publication. Evidence-based revisions are made within 5 years or sooner, if there are significant changes in the evidence.

Academy of Breastfeeding Medicine Protocol Committee Kathleen A. Marinelli, MD, FABM, Chairperson Maya Bunik, MD, MSPH, FABM, Co-Chairperson Larry Noble, MD, FABM, Translations Chairperson Nancy Brent, $M D$

Ruth A. Lawrence, MD, FABM

Sarah Reece-Stremtan, MD Casey Rosen-Carole, MD Tomoko Seo, MD, FABM Rose St. Fleur, MD Michal Young, MD

For correspondence: abm@bfmed.org 